\title{
The L-arginine/nitric oxide/cyclic-GMP pathway apparently mediates the peripheral antihyperalgesic action of fentanyl in rats
}

F.A.B. Maegawa and C.R. Tonussi
Departamento de Farmacologia, Universidade Federal de Santa Catarina, Florianópolis, SC, Brasil

\section{Correspondence \\ C.R. Tonussi \\ R. Ferreira Lima, 82 \\ 88015-420 Florianópolis, SC \\ Brasil \\ Fax: +55-48-222-4164 \\ E-mail: tonussi@farmaco.ufsc.br}

Research supported by CNPq (No. 351103/97-0). F.A.B. Maegawa was the recipient of an undergraduate fellowship from $\mathrm{CNPq} / \mathrm{PIBIC}-U F S C$.

Received September 4, 2002 Accepted August 29, 2003

\begin{abstract}
There are only a few studies on the molecular mechanisms underlying the peripheral antihyperalgesic effect of opioids. The aim of this study was to investigate the molecular bases of the peripheral antihyperalgesic effect of fentanyl in a model of prostaglandin-induced chemical hyperalgesia. Prostaglandin $\mathrm{E}_{2}(1.4 \mathrm{nmol})$ injected into one hind paw of male Wistar rats (200-250 g, N = 6 in each experimental or control group) pretreated with indomethacin $(2.5 \mathrm{mg} / \mathrm{kg})$ potentiated the nocifensive response to formalin (1\%) injection made $60 \mathrm{~min}$ later. Drugs applied locally $30 \mathrm{~min}$ after prostaglandin $\mathrm{E}_{2}$ induced the following effects: fentanyl $(0.1-1.0 \mathrm{nmol})$ caused a dose-dependent reversal of the hyperalgesic state, naloxone $(2 \mathrm{nmol})$ co-injected with fentanyl $(1 \mathrm{nmol})$ completely reversed the antihyperalgesic effect, $\mathrm{N}^{\omega_{-}}$ nitro-L-arginine (NOARG, 0.05-0.2 $\mu \mathrm{mol}$ ) in combination with fentanyl $(1.0 \mathrm{nmol})$ caused a dose-dependent inhibition of the antihyperalgesic effect of fentanyl, co-administration of L-arginine $(0.5 \mu \mathrm{mol})$ with NOARG $(0.2 \mu \mathrm{mol})$ plus fentanyl $(1.0 \mathrm{nmol})$ fully restored the antihyperalgesic effect, and the cyclic-GMP phosphodiesterase inhibitor UK-114,542-27 (5-[2-ethoxy-5-(morpholinylacetyl) phenyl]-1,6dihydro-1-methyl-3-propyl-7H-pyrazolo [4,3-d]-pyrimidin-7-one methanesulfonate monohydrate; 0.5-2.0 $\mu \mathrm{mol}$ ) potentiated a subeffective dose of fentanyl $(0.1 \mathrm{nmol})$ in a dose-dependent manner. However, UK-114,542-27 (2.0 umol) injected alone did not produce this antihyperalgesic effect. Systemically administered fentanyl (1.0 nmol, $s c$ ) did not cause antinociception. Taken together, these results support the view that fentanyl reverses prostaglandin $\mathrm{E}_{2}$-induced hyperalgesia, probably by activating an opioid receptor at the periphery, and furthermore the L-arginine/nitric oxide/cyclic-GMP pathway may mediate this peripheral effect of fentanyl.
\end{abstract}

\section{Introduction}

Sensitization of nociceptors is common to all types of inflammatory pain. Analgesic drugs that act specifically upon inflamma-
Key words - Opioid

- Guanylate cyclase

- Prostaglandin

- PDE5

- UK-114,542-27 tory sites may either prevent sensitization of the nociceptors or directly antagonize the ongoing hyperalgesia (1). The antihyperalgesia produced by aspirin-like drugs is currently explained by blockade of the synthesis 
of locally released prostaglandins, thus preventing sensitization of the nociceptors. Inhibition of prostaglandin synthesis, however, is also responsible for the most common undesirable side effects, such as gastric erosion or delayed blood clotting. As an emerging alternative, several different compounds have been reported to be able to directly antagonize inflammatory hyperalgesia without preventing prostaglandin biosynthesis in animal models. Acetylcholine and sodium nitroprusside (2), diclofenac (3), dipyrone (4), ketorolac (5) and opioid agonists $(6,7)$ have a direct peripheral inhibitory effect on the hyperalgesia induced by inflammation or inflammatory mediators. Among these drugs, the peripheral antihyperalgesic effect of opioids has been most intensely investigated, and has been shown to be mediated by $\mu, \delta$ or $\kappa$ receptor subtypes, apparently depending on the sensitization protocol (8-12). At the molecular level, it has been proposed that the L-arginine/nitric oxide/cyclic-GMP (cGMP) pathway mediates the peripheral antihyperalgesic effect of opioids, although only morphine has been studied thus far $(13,14)$. In addition, morphine-nitric oxide coupling has been studied in prostaglandininduced mechanical hyperalgesia, but has yet to be systematically investigated with other types of stimuli.

Thus, despite the clinical importance of the development of a drug which could reverse inflammatory hyperalgesia without the side effects related to nonsteroidal antiinflammatory drugs, studies of the molecular mechanisms underlying the peripheral antihyperalgesia produced by opioids are scarce. Consequently, the participation of the nitric oxide/cGMP pathway in the peripheral antinociceptive effect of other types of opiate-like drugs has not been firmly established.

In view of these considerations, we evaluated the peripheral effect of the meperidine derivative fentanyl, which is structurally different from morphine, in a model of prosta- glandin $\mathrm{E}_{2}$ - $\left(\mathrm{PGE}_{2}\right)$ induced hyperalgesia followed by chemical stimulation with formalin.

\section{Material and Methods}

\section{Animals}

Experiments were performed on male Wistar rats (200-250 g) housed in temperature-controlled rooms $\left(22-25^{\circ} \mathrm{C}\right)$ under a 12 12-h light/dark cycle with free access to water and food. All experiments were conducted according to the ethical guidelines of the International Association for the Study of Pain (15) and were approved by the local ethics committee for animal research.

\section{Hyperalgesia model}

Formalin $(1 \%, 50 \mu \mathrm{l})$ was injected $s c$ under the dorsal surface of one hind paw of indomethacin-treated $(2.5 \mathrm{mg} / \mathrm{kg}$, ip, $1 \mathrm{~h}$ before) rats, 30, 60 and 150 min after a $\mathrm{PGE}_{2}$ $(1.4 \mathrm{nmol} / 50 \mu \mathrm{l})$ injection. The acts of lifting and shaking of the injected paw were counted and summed over a 5-min period immediately after formalin injection (number of lifting and shaking movements). The highest intensity response to formalin injections made 30 and 60 min after $\mathrm{PGE}_{2}$ was recorded. When formalin was applied $150 \mathrm{~min}$ after $\mathrm{PGE}_{2}$ there was no potentiation of the response to formalin compared to control values (Figure 1). Thus, formalin was always administered 60 min after $\mathrm{PGE}_{2}$, with pharmacological intervention $30 \mathrm{~min}$ before the formalin injection. This schedule permitted the optimal management of the three injections given to each animal. The period between 0 and 5 min after formalin injection was characterized by a massive response by $\mathrm{PGE}_{2}$-treated animals compared to untreated animals. However, a small and variable response was observed between 10 and $60 \mathrm{~min}$ after formalin; as a result, this second phase response to formalin was considered to be unreliable for quantification of the effect of 
the previous $\mathrm{PGE}_{2}$ injection and was excluded from the test. Indomethacin was diluted in Tris buffer, $\mathrm{pH}$ 8.0, and $\mathrm{PGE}_{2}$ was diluted in saline from an absolute ethanol stock solution of $500 \mu \mathrm{g} / \mathrm{ml}$.

After the 5-min period of observation, all animals were killed by cervical dislocation. The indomethacin dose used throughout this study produced maximal inhibition in a model of carrageenan-induced rat paw edema used in our laboratory (data not shown) and therefore was considered sufficient for the purpose of blocking endogenous prostaglandin release.

\section{Drugs}

The following drugs were used: L-arginine (MW = 174.2; Sigma, St. Louis, MO, USA) fentanyl citrate (MW = 528.6; Cristália do Brasil S/A, Itapira, SP, Brazil), formalin (Merck AG, Darmstadt, Germany), indomethacin (Prodrome Química e Farmacêutica, Campinas, SP, Brazil), naloxone hydrochloride (MW = 363.8; Sigma), $\mathrm{N}^{\omega_{-}}$ nitro-L-arginine (NOARG, MW = 219.2; Sigma), $\mathrm{PGE}_{2}$ (Sigma) and UK-114,542-27 (5-[2-ethoxy-5-(morpholinylacetyl) phenyl]1,6-dihydro-1-methyl-3-propyl-7H-pyrazolo [4,3-d]-pyrimidin-7-one methanesulfonate monohydrate; MW = 553.6). UK-114,54227 was kindly donated by Pfizer Global Research and Development, Sandwich, UK.

\section{Specific inhibition of phosphodiesterases by UK-114,542-27}

The potency of UK-114,542-27 as an inhibitor of phosphodiesterase (PDE) activity was determined using a modification of the two-step radioisotopic procedure of Thompson and Appleman (16) as described in Ref. 17. $\left[{ }^{3} \mathrm{H}\right]$-cGMP $(0.5 \mu \mathrm{M})$ was used as the substrate for PDE1, 2, 5 and 6 and $\left[{ }^{3} \mathrm{H}\right]-$ cAMP $(0.5 \mu \mathrm{M})$ for PDE3 and 4. PDE2, 3 and 5 were partially purified from human corpus cavernosum, PDE1 from human cardiac ventricle, PDE4 from skeletal muscle

and PDE6 from bovine retina as described in Ref. 17. Pfizer Global Research and Development supplied the $\mathrm{IC}_{50}$ values and respective confidence intervals as shown in Table 1.

\section{Statistical analysis}

One-way ANOVA with the Bonferroni post-test was performed using GraphPad Prism version 3.00 for Windows (Graph Pad Software, San Diego, CA, USA; www. graphpad.com). The results reported in the graphs are the mean \pm SEM of six animals.

\section{Results}

\section{Antihyperalgesic effect of fentanyl}

Fentanyl (0.1-1.0 nmol) applied $30 \mathrm{~min}$

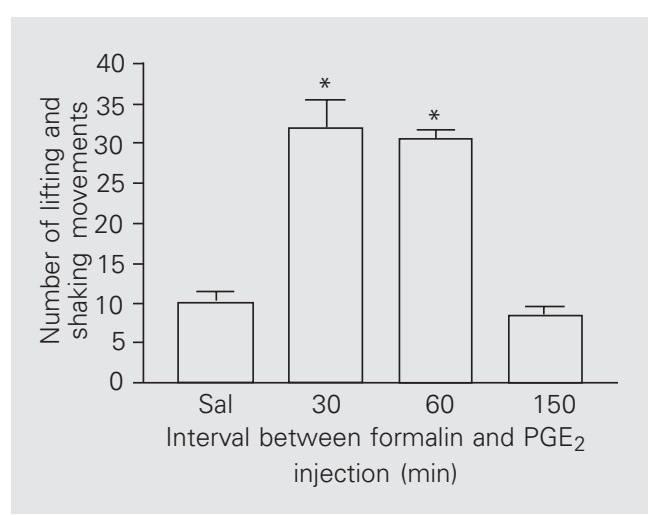

Figure 1. Time dependence of prostaglandin $E_{2-}\left(\mathrm{PGE}_{2}\right)$ induced hyperalgesia. $\mathrm{PGE}_{2}(500 \mathrm{ng} / 50 \mu \mathrm{l})$ was injected under the dorsal surface of the right hind paw of animals pretreated with indomethacin $(2.5 \mathrm{mg} / \mathrm{kg}$, ip, $1 \mathrm{~h}$ before). Formalin $(1 \% / 50 \mu \mathrm{l})$ was injected into the same site at 30 , 60 or 150 min after $\mathrm{PGE}_{2}$ injection. The number of lifting and shaking movements was recorded for 5 min immediately after formalin injection. The control group (Sal) received an injection of saline $(50 \mu \mathrm{l} / \mathrm{paw})$ instead of $\mathrm{PGE}_{2} 60$ min before formalin injection. Bars indicate the mean \pm SEM of 6 animals in each group. ${ }^{*} P<0.01$ compared to control (ANOVA followed by Bonferroni's test).

Table $1 . \quad \mathrm{C}_{50}$ values and respective confidence intervals.

\begin{tabular}{lcc}
\hline PDE & $\begin{array}{c}\text { Geometric mean } \\
I C_{50}(\mathrm{nM})\end{array}$ & $\begin{array}{c}95 \% \text { Confidence } \\
\text { interval }\end{array}$ \\
\hline PDE1 & $93(\mathrm{~N}=5)$ & $60-147$ \\
PDE2 & $42,000(\mathrm{~N}=7)$ & $31,000-59,000$ \\
PDE3 & $27,000(\mathrm{~N}=4)$ & $15,000-50,000$ \\
PDE4 & $9,100(\mathrm{~N}=4)$ & $7,200-11,500$ \\
PDE5 & $1.7(\mathrm{~N}=12)$ & $1.1-2.7$ \\
PDE6 & $4.5(\mathrm{~N}=4)$ & $1.8-11.3$ \\
\hline
\end{tabular}

$\mathrm{PDE}=$ phosphodiesterase . 


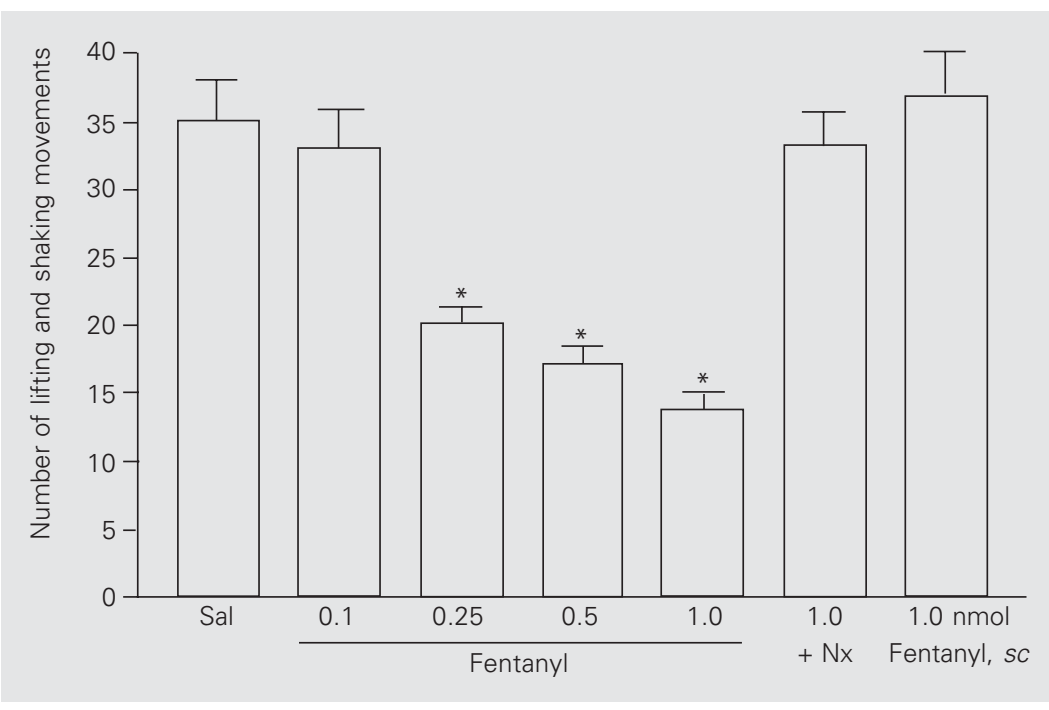

Figure 2. Peripheral antihyperalgesic effect of fentanyl. Fentanyl $(0.1-1.0 \mathrm{nmol} / 50 \mu \mathrm{l} / \mathrm{paw})$ was injected 30 min after paw injection of $\mathrm{PGE}_{2}$ and reversed the effect of $\mathrm{PGE}_{2}$ on the nocifensive responses to formalin injection. The $\mathrm{Nx}$ bar indicates the group that received fentanyl $(1.0 \mathrm{nmol})$ plus naloxone $(2 \mathrm{nmol})$. The highest dose of fentanyl $(1.0 \mathrm{nmol})$ did not reverse the effect of $\mathrm{PGE}_{2}$ when injected systemically $(s c)$. Bars indicate the mean $\pm \mathrm{SEM}$ of 6 animals in each group. The control group (Sal) received saline instead of fentanyl. ${ }^{*} \mathrm{P}<$ 0.001 compared to control (ANOVA followed by Bonferroni's test).

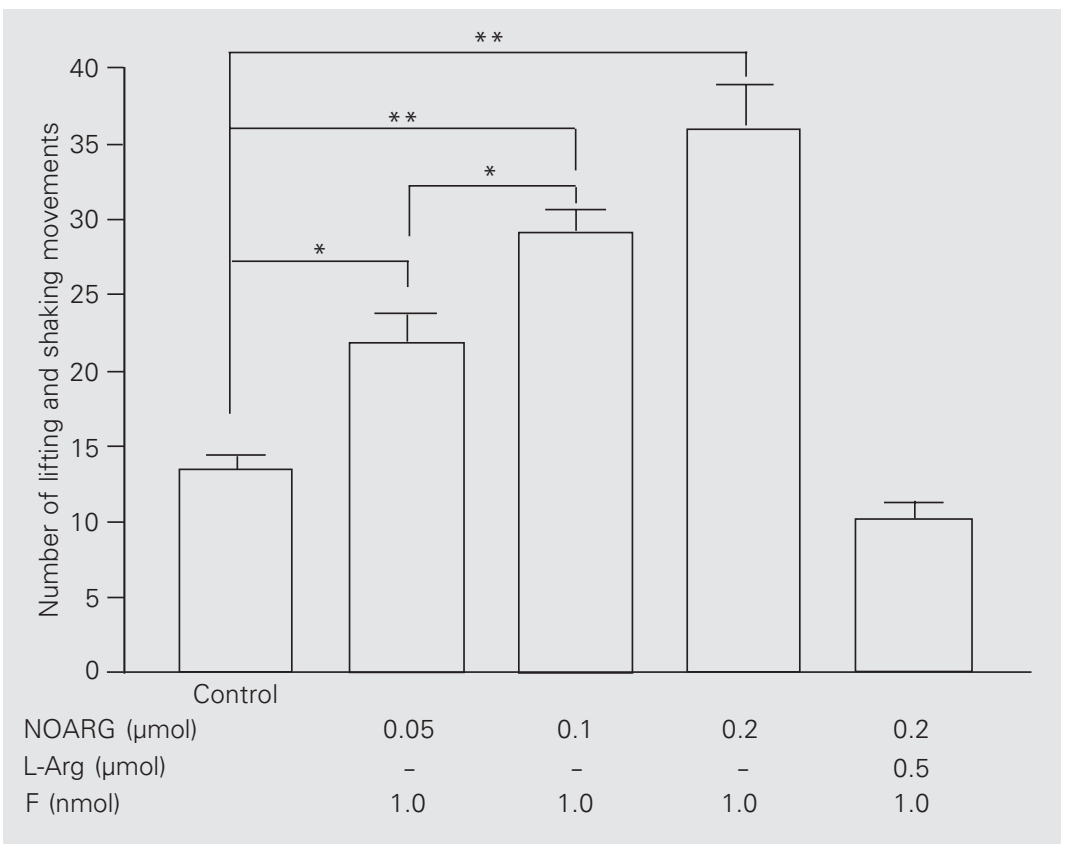

Figure 3. Reversal of the antihyperalgesic effect of fentanyl (F) by $N^{\omega}$-nitro-L-arginine (NOARG). Increasing doses of NOARG (0.05-0.2 $\mu$ mol) co-injected with fentanyl $(1.0 \mathrm{nmol})$ 30 min before formalin injection caused a progressive inhibition of the antihyperalgesic effect of the opioid. The effect of fentanyl was fully restored when L-arginine (L-Arg; 0.5 $\mu \mathrm{mol})$ was added to the NOARG-fentanyl mixture. The control group received only fentanyl $(1.0 \mathrm{nmol})$, without NOARG, between the $\mathrm{PGE}_{2}$ and formalin injections. The bars indicate the mean \pm SEM of 6 animals in each group. ${ }^{*} P<0.05,{ }^{*} P<0.001$ for comparison to control or between doses (ANOVA followed by Bonferroni's test). after $\mathrm{PGE}_{2}$ injection caused a progressive inhibition of the potentiation by $\mathrm{PGE}_{2}$ of the nociceptive response elicited by formalin. Significant differences from the saline-treated control group were detected at the doses of $0.2,0.5$, and $1.0 \mathrm{nmol}(\mathrm{P}<0.001)$. The highest effective dose of fentanyl $(1 \mathrm{nmol} /$ paw) co-injected with the nonspecific opioid receptor antagonist naloxone $(2 \mathrm{nmol} / \mathrm{paw})$ did not antagonize the prostaglandin-induced effect, suggesting that the effect of fentanyl was mediated by an opioid receptor. To exclude the possibility that a central opioid effect could account for the antinociceptive action of fentanyl observed in the present study, the highest opioid dose (1 nmol) was injected $s c$ under the neck skin of the animals (Figure 2), with no effect observed. Finally, when fentanyl (1 nmol) was applied without previous $\mathrm{PGE}_{2}$ sensitization, no change was observed in the formalin-induced response (data not shown in the figure). In this case, the saline-treated group presented $15.0 \pm 1.2$ lifting and shaking movements and the fentanyl-treated group presented 14.3 $\pm 1.3(\mathrm{P}>0.05$, unpaired $t$-test $)$.

\section{Dose-dependent inhibition of the antihyperalgesic effect of fentanyl by $\mathrm{N}^{\omega}$-nitro-L-arginine}

To determine whether nitric oxide synthase (NOS) activity mediates the peripheral analgesic effect of fentanyl, we co-injected the maximal analgesic dose of fentanyl previously tested $(1.0 \mathrm{nmol})$ with increasing doses of the NOS inhibitor NOARG (0.05, 0.1 and $0.2 \mu \mathrm{mol})$. These treatments were applied $30 \mathrm{~min}$ before the formalin injection. The NOARG-fentanyl mixture progressively lost its effect as the NOARG content was increased $(0.05 \mu \mathrm{mol}, \mathrm{P}<0.05 ; 0.1$ and 0.2 $\mu \mathrm{mol}, \mathrm{P}<0.001)$ compared to the effect of fentanyl alone (Figure 3). The antihyperalgesic effect was restored when L-arginine $(0.5 \mu \mathrm{mol})$ was added to the NOARG-fentanyl mixture. 


\section{Dose-dependent potentiation of antihyperalgesia by UK-114,542-27, a specific cGMP phosphodiesterase inhibitor}

Increasing doses of UK-114,542-27 (0.5, 1 and $2 \mu \mathrm{mol}$ ) co-injected with a subeffective dose of fentanyl $(0.1 \mathrm{nmol}) 30 \mathrm{~min}$ before formalin injection produced a significant dose-dependent antihyperalgesia compared to control $(0.5 \mu \mathrm{mol}, \mathrm{P}<0.05 ; 1$ and $2 \mu \mathrm{mol}$, $\mathrm{P}<0.001)$ and a significant difference was also detected between the doses of 0.5 and 2 $\mu \mathrm{mol}$ of the PDE inhibitor $(\mathrm{P}<0.05)$. The maximal potentiating dose of UK-114,542$27(2 \mu \mathrm{mol})$ did not cause any antihyperalgesic effect when administered alone (Figure 4).

\section{Discussion}

We report here the antihyperalgesic action of the $\mu$-opioid receptor agonist fentanyl (18) injected locally in a model of $\mathrm{PGE}_{2}-$ induced hyperalgesia in response to formalin. This effect was dose-related, and could not be attributed to a central action of the opioid since the maximally effective dose of locally injected fentanyl had no effect when injected $s c$ under the rat's neck skin.

$\mathrm{PGE}_{2}$ caused maximal potentiation of the nocifensive responses to formalin when injected either 30 or 60 min before, but no potentiation was recorded when $\mathrm{PGE}_{2}$ was given $150 \mathrm{~min}$ before formalin. This timedependent effect was closely similar to that observed for $\mathrm{PGE}_{2}$ in models of thermal (19) and mechanical (20) stimulation, suggesting that $\mathrm{PGE}_{2}$ has a similar effect on the nociceptive system independent of the kind of stimulus. Fentanyl caused a clear dose-dependent inhibition of the formalin-induced response only when $\mathrm{PGE}_{2}$ was given previously (Figure 2). This finding suggests that the opioid specifically reversed the potentiating effect of $\mathrm{PGE}_{2}$ on the formalin response, but did not exert, for example, an anesthetic-like effect. For this reason, the peripheral effect of fentanyl may be understood as antihyperalgesic rather than antinociceptive effect, since it did not affect the nonpotentiated formalin nociceptive response. In addition, this fentanyl-induced peripheral antihyperalgesia appears to be due to an action on an opioid receptor, since it was blocked by the local injection of naloxone.

The involvement of the L-arginine/nitric oxide/cGMP pathway in the peripheral action of fentanyl was assessed by injecting a mixture of the NOS inhibitor NOARG and fentanyl (Figure 3). The progressive decrease in the antihyperalgesic effect of fentanyl as the content of NOARG was increased in the mixture suggests that nitric oxide formation also mediates the peripheral effect of fentanyl. Furthermore, the cGMP PDE inhibitor UK-114,542-27 (Figure 4) dose-dependently potentiated a subeffective dose of fenta-

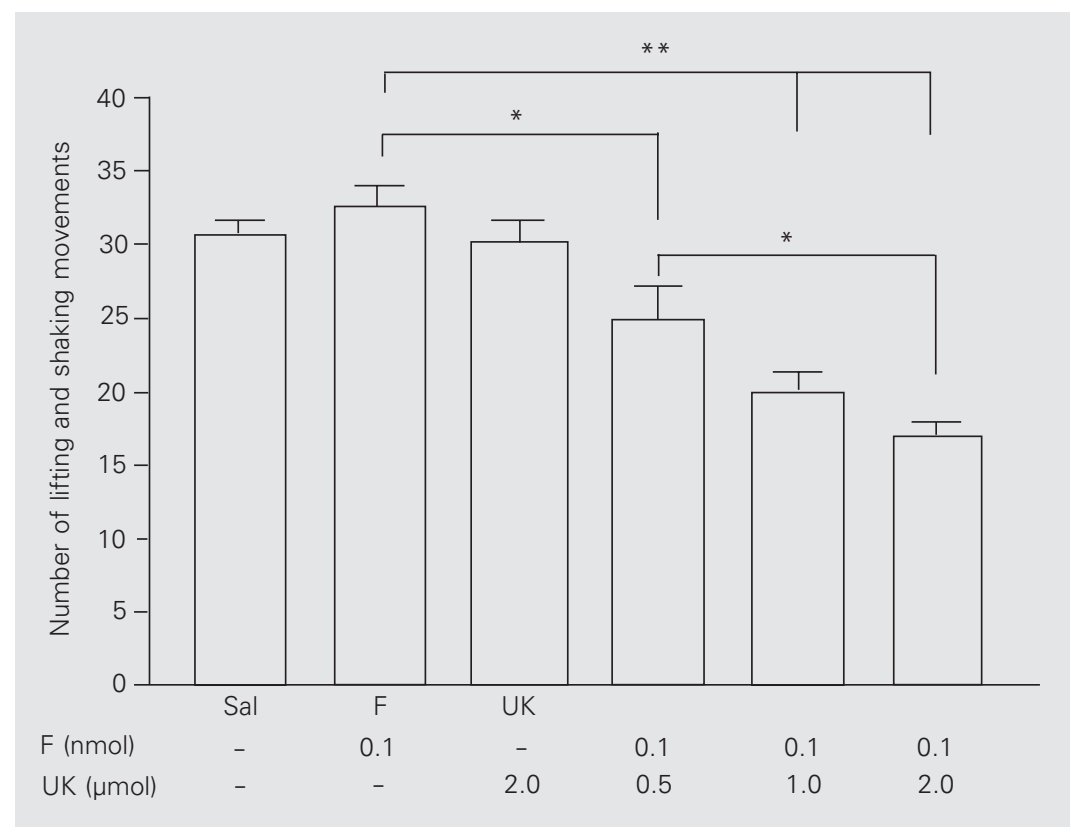

Figure 4. Potentiation of the effect of fentanyl by the type 5 phosphodiesterase (PDE5) inhibitor UK-114,542-27 (UK). Increasing doses of the inhibitor (0.5-2.0 $\mu \mathrm{mol})$ co-injected with a subeffective dose of fentanyl (F; $0.1 \mathrm{nmol}) 30$ min before formalin injection caused a dose-dependent inhibition of the nocifensive responses. The Sal group received only saline between the $\mathrm{PGE}_{2}$ and formalin injections. The fentanyl control group (F) and the UK control group (UK) only received the subeffective dose of the opioid and the highest dose of UK, respectively, between the $\mathrm{PGE}_{2}$ and formalin injections. The bars indicate the mean \pm SEM of 6 animals in each group. ${ }^{*} P<0.05,{ }^{*} P<0.001$ for comparison to fentanyl control or between doses (ANOVA followed by Bonferroni's test). 
nyl. The specificity of UK-114,542-27 for PDE5 supports the idea that cGMP formation at the periphery is also important for the expression of the antihyperalgesic effect of the opioid. Overall, our data support the hypothesis that the L-arginine/nitric oxide/ cGMP pathway mediates the peripheral effect of fentanyl.

The first attempt to address the molecular mechanism mediating the peripheral antinociceptive action of opioids was made by Ferreira et al. (13), who demonstrated that morphine antagonized the $\mathrm{PGE}_{2}$-induced mechanical hyperalgesia by means of nitric oxide-induced cGMP formation. In an effort to extend this finding to the well-known formalin nociceptive test, Granados-Soto et al. (21) inhibited the peripheral action of morphine using either the NOS inhibitor NOARG or the guanylate cyclase inhibitor methylene blue. Unfortunately, methylene blue also potently inhibits both endothelial (22) and neuronal NOS (23), thus precluding a conclusion about the participation of cGMP in the peripheral effect of morphine. The potentiating effect of UK-114,542-27 coinjected with fentanyl not only supports a role for cGMP formation in the peripheral opioid effect, but also identifies PDE5 as a molecular target for peripheral modulation of opioid analgesia.

Several lines of evidence converge to explain how opioids can antagonize inflammatory hyperalgesia at the peripheral level. It has long been known that $\mu$-receptor sub- type activation causes hyperpolarization of neurons by opening $\mathrm{K}^{+}$-channels (24), and, indeed, an ATP-sensitive $\mathrm{K}^{+}$-channel accounts for the peripheral antinociceptive action of morphine in a model of mechanical hyperalgesia (14). However, other $\mathrm{K}^{+}$-channel types may also be involved in morphineinduced hyperpolarization of primary afferent neurons (25). Furthermore, a $\mu$-opioid receptor subtype was shown to be coupled to nitric oxide release in endothelial cells (26), and nitric oxide and cGMP can drive potassium channel opening in a smooth muscle assay $(27,28)$.

The present study extends previously reported data on the peripheral analgesic effect of morphine, demonstrating that fentanyl acts in opposition to the hyperalgesic effect of $\mathrm{PGE}_{2}$, and that this action is probably mediated by the L-arginine/nitric oxide/ cGMP pathway. The direct antagonism of $\mathrm{PGE}_{2}$-induced hyperalgesia remains an alternative to the development of new peripheral analgesics and, by preserving the endogenous production of prostaglandins, this would be safer than aspirin-like drugs. The model of $\mathrm{PGE}_{2}$-induced hyperalgesia in response to formalin is a straightforward approach to test this kind of peripheral effect with great specificity and reliability, since it is insensitive to prostaglandin synthesis inhibitors. In addition, the results of the present study suggest that clinically available PDE5 inhibitors may be effective adjuvants for opioid analgesia.

\section{References}

1. Ferreira SH (1990). A classification of peripheral analgesics based upon their mode of action. In: Sandler M \& Collins GM (Editors), Migraine: Spectrum of Ideas. Oxford University Press, New York.

2. Duarte IDG, Lorenzetti BB \& Ferreira SH (1990). Peripheral analgesia and activation of the nitric oxide-cyclic GMP pathway. European Journal of Pharmacology, 186: 289-293.

3. Tonussi CR \& Ferreira SH (1994). Mechanism of diclofenac analgesia: direct blockade of inflammatory sensitization. European Journal of Pharmacology, 251: 173-179.

4. Lorenzetti BB \& Ferreira SH (1996). Activation of the arginine-nitric oxide pathway in primary sensory neurons contributes to dipyroneinduced spinal and peripheral analgesia. Inflammation Research, 45: 308-311.

5. Lazaro-lbanez GG, Torres-Lopez JE \& Granados-Soto V (2001). Participation of the nitric oxide-cyclic GMP-ATP-sensitive $\mathrm{K}^{+}$channel pathway in the antinociceptive action of ketorolac. European Journal of Pharmacology, 426: 39-44.

6. Ferreira SH \& Nakamura M (1979). II-Prostaglandin hyperalgesia: the peripheral analgesic activity of morphine, enkephalins and opioid antagonists. Prostaglandins, 18: 191-200. 
7. Ferreira SH \& Nakamura M (1979). III-Prostaglandin hyperalgesia: relevance of the peripheral effect for analgesic action of opioidantagonists. Prostaglandins, 18: 201-208.

8. Lorenzetti BB \& Ferreira SH (1982). The analgesic effect of quaternary analogues of morphine and nalorphine. Brazilian Journal of Medical and Biological Research, 15: 285-290.

9. Rios L \& Jacob JJ (1983). Local inhibition of inflammatory pain by naloxone and its N-methyl quaternary analogue. European Journal of Pharmacology, 96: 277-283.

10. Ferreira SH, Lorenzetti BB \& Rae GA (1984). Is methylnalorphinium the prototype of an ideal peripheral analgesic? European Journal of Pharmacology, 99: 23-29.

11. Levine JD \& Taiwo YO (1989). Involvement of $\mu$-opiate receptor in peripheral analgesia. Neuroscience, 32: 571-575.

12. Taiwo YO \& Levine JD (1991). $\kappa$ - and $\delta$-opioids block sympathetically dependent hyperalgesia. Journal of Neuroscience, 11: 928-932.

13. Ferreira SH, Duarte IDG \& Lorenzetti BB (1991). The molecular mechanism of action of peripheral morphine analgesia: stimulation of the cGMP system via nitric oxide release. European Journal of Pharmacology, 201: 121-122.

14. Rodrigues ARA \& Duarte IDG (2000). The peripheral antinociceptive effect induced by morphine is associated with ATP-sensitive $\mathrm{K}^{+}$channels. British Journal of Pharmacology, 129: 110-114.

15. International Association for the Study of Pain (1983). Ethical guidelines for investigation of experimental pain in conscious animals. Pain, 16: 109-110.

16. Thompson WJ \& Appleman MM (1971). Multiple cyclic nucleotide phosphodiesterase activities from rat brain. Biochemistry, 10: 311316.

17. Ballard SA, Gingell CJ, Tang K, Turner LA, Price ME \& Naylor AM (1998). Effects of sildenafil on the relaxation of human corpus cavernosum tissue in vitro and on the activities of cyclic nucleotide phosphodiesterase isozymes. Journal of Urology, 159: 2164-2171.

18. Villiger JW, Ray LJ \& Taylor KM (1983). Characteristics of $\left[{ }^{3} \mathrm{H}\right]$ fentanyl binding to the opiate receptor. Neuropharmacology, 22: 447-452.

19. Negus SS, Butelman ER, Al Y \& Woods JH (1993). Prostaglandin $E_{2}-$ induced thermal hyperalgesia and its reversal by morphine in the warm-water tail-withdrawal procedure in rhesus monkeys. Journal of Pharmacology and Experimental Therapeutics, 266: 1355-1363.

20. Ouseph AK, Khasar SG \& Levine JD (1995). Multiple second messenger systems act sequentially to mediate rolipram-induced prolongation of prostaglandin $E_{2}$-induced mechanical hyperalgesia in the rat. Neuroscience, 64: 769-776.

21. Granados-Soto V, Rufino MO, Gomes-Lopes LD \& Ferreira SH (1997). Evidence for the involvement of the nitric oxide-cGMP pathway in the antinociception of morphine in the formalin test. European Journal of Pharmacology, 340: 177-180.

22. Mayer B, Brunner F \& Schmidt K (1993). Inhibition of nitric oxide synthesis by methylene blue. Biochemical Pharmacology, 45: 367374.

23. Volke V, Wegener G, Vasar E \& Rosenberg R (1999). Methylene blue inhibits hippocampal nitric oxide synthase activity in vivo. Brain Research, 826: 303-305.

24. North RA, Williams JT, Surprenant A \& Christie MJ (1987). Mu and delta receptors belong to a family of receptors that are coupled to potassium channels. Proceedings of the National Academy of Sciences, USA, 84: 5487-5491.

25. Yonehara N \& Takiuchi S (1997). Involvement of calcium-activated potassium channels in the inhibitory prejunctional effect of morphine on peripheral sensory nerves. Regulatory Peptides, 68: 147153.

26. Stefano GB, Hartman A, Bilfinger TV, Magazine HI, Liu Y, Casares F \& Goligorsky MS (1995). Presence of the $\mu 3$ opiate receptor in endothelial cells. Coupling to nitric oxide production and vasodilation. Journal of Biological Chemistry, 270: 30290-30293.

27. Bolotina VM, Najibi S, Palacino JJ, Pagano PJ \& Cohen RA (1994). Nitric oxide directly activates calcium-dependent potassium channels in vascular smooth muscle. Nature, 368: 850-853.

28. Tanigushi J, Furukawa KI \& Shigekawa M (1993). Maxi K+ channels are stimulated by cyclic guanosine monophosphate-dependent protein kinase in canine coronary artery smooth muscle cells. Pflügers Archiv. European Journal of Physiology, 423: 167-172. 